\title{
Development of dyspnea on young female patient with $D$ transposition of great arteries operated by Senning procedure
}

\author{
Vesna Pehar Pejčinović ${ }^{*}$, Dragan Javoran1, Željko Madžar', Rajko Miškulin², Marko Boban', Viktor \\ Peršić \\ ${ }^{1}$ Thalassotherapija Opatija, Opatija, Croatia \\ ${ }^{2}$ University Hospital Center Rijeka, Rijeka, Croatia
}

Complete transposition of the great arteries is common congenital hearth disease in new-borns and infants. In this malformation, origination of the aorta is in the right ventricle and origination of the pulmonary artery is in the left ventricle. Systemic venous blood returns through the right atrium to the right ventricle and then to the aorta, and pulmonary venous blood returns trought left atrium to the left ventricule and then to the pulmonary artery. In these circumstances after birth, the life is sustained with existing communication between right and left circulation, eg. ventricular septal defect, atrial septal defect or patent ductus arteriosus. Clinical manifestations are dyspnea, cyanosis, hypoxemia and congestive hearth failure. Surgical management options are:

1. atrial switch procedure that was developed in 1950s (either Mustard or Senning operation), or

2. arterial switch procedure that was developed in 1980s.

After the first one, most patients in the adulthood (up to $40 \%$ ) have mild/sever tricuspidal regurgitation, relative right ventricular ischaemia and signs of the right ventricular dysfunction, pulmonary hypertension, obstruction of the venous conduit, or obstruction of the pulmonal venous baffle, rhytm disturbances as well as shortened life expectancy. After arterial switch procedure patients who reach adulthood can develope neopulmonary or neoaortic valve disturbances, rhytm disturbances, coronary artery disease.

In our case report, young female, 24 years old, who underwent Senning operation in the childhood, is now presented with signs of dyspnoea on exercise. In our examinations (echocardiography, cardiac MRI) we have shown the cause of the same: subvalvular stenosis of the pulmonary valve, with high gradient trough the left ventricule outflow tract and the fistula between the venous conduit and right atrium. Now, we consider the further treatment options in this patient.

KEYWORDS: D transposition of great arteries, Senning procedure, subvalvular stenosis of the pulmonary valve.

\section{Received: $20^{\text {th }}$ Mar 2013}

*Address for correspondence: Thalassotherapija Opatija, Maršala Tita 188/1, HR51410 Opatija, Croatia.

Phone: +385-51-202-724

E-mail: pehar.vesna@gmail.com

\section{Literature}

1. Kramer CM, Barkhausen J, Flamm SD, Kim RJ, Nagel E; Society for Cardiovascular Magnetic Resonance Board of Trustees Task Force on Standardized Protocols. Standardized cardiovascular magnetic resonance imaging (CMR) protocols, society for cardiovascular magnetic resonance: board of trustees task force on standardized protocols. J Cardiovasc Magn Reson. 2008;10:35.

2. Hornung TS, Derrick GP, Deanfield JE, Redington AN. Transposition complexes in the adult: a changing perspective. Cardiol Clin. 2002;20:405-20.

3. Kammeraad JA, van Deurzen CH, Sreeram N, Bink-Boelkens MT, Ottenkamp J, Helbing WA, et al. Predictors of sudden cardiac death after Mustard or Senning repair for transposition of the great arteries. J Am Coll Cardiol. 2004;44:1095-102. 